\title{
Administração oral de peptídeos e proteínas: II. Aplicação de métodos de microencapsulação
}

\author{
Catarina Silva', António Ribeiro², Domingos Ferreira3 ${ }^{3}$, Francisco Veiga ${ }^{1 *}$ \\ 'Laboratório de Tecnologia Farmacêutica, Faculdade de Farmácia, Universidade de Coimbra, Coimbra, Portugal, \\ ${ }^{2}$ Laboratório de Tecnologia Farmacêutica, Instituto Superior da Ciências da Saúde do Norte, Gandra, Paredes, \\ Portugal, '²aboratório de Tecnologia Farmacêutica, Faculdade de Farmácia, Universidade do Porto, Porto, Portugal
}

*Correspondência:

F. Veiga

Faculdade de Farmácia

Universidade de Coimbra

3000 Coimbra

Portugal

E-mail: fveiga@ci.uc.pt
A escolha de um método de Microencapsulação adequado para promover o aumento da biodisponibilidade oral de fármacos peptídicos depende das características físico-químicas do fármaco a encapsular, das condições operacionais e dos polímeros utilizados. Nesta abordagem é feita uma avaliação dos diversos métodos de Microencapsulação e sua aplicação na administração oral de peptídeos e proteínas. As técnicas de Microencapsulação que utilizam polimeros de origem natural, não recorrendo a condições drásticas de preparação, são consideradas opções privilegiadas.

\section{INTRODUÇÃO}

Na primeira parte desta revisão (Silva et al., 2002b) foram descritos os obstáculos associados à administração oral de peptídeos e proteínas, bem como as estratégias possíveis a adotar para alcançar esse fim. A administração oral de fármacos peptídicos é limitada, principalmente, pela intensa degradação enzimática no trato gastro-intestinal (GI) e fraca permeabilidade através da mucosa intestinal. Os inconvenientes associados à administração parenteral têm impulsionado o recurso a vias de administração alternativas. Com o objetivo de aumentar a biodisponibilidade oral de peptídeos e proteínas foram desenvolvidas diversas estratégias, nomeadamente, a utilização de inibidores das enzimas proteolíticas (BernkopSchnurch, 1998), promotores da absorção (Fix, 1996), modificação química (Bundgaard, 1992) e formulações farmacêuticas específicas, como sistemas particulados (Allemann, Leroux, Gurny, 1998), emulsões (Sarciaux,
Acar, Sado, 1995; Trenktrog, Muller, Seifert, 1995), sistemas vetorizados (Carino, Mathiowitz, 1999; Rubinstein et al., 1997; Shah, Shen, 1996) e sistemas bioadesivos (Lehr, 2000; Lueben et al., 1997). A combinação de várias estratégias, de forma a ultrapassar ambas as barreiras à absorção poderá ser vantajosa (Bernkop-Schnurch, 1998; Geary, Schlameus, 1993; Hosny et al., 1998; Morishita et al., 1992; Suzuki et al., 1998). Na primeira parte da revisão, foi concluído que a microencapsulação é uma alternativa válida, pelo fato de as micropartículas constituírem sistemas nas quais diferentes estratégias podem ser adaptadas de forma a proteger os fármacos da degradação enzimática e aumentar a permeabilidade através do epitélio intestinal.

A estrutura complexa das proteínas, responsável pela sua atividade biológica, leva a problemas de formulação porque são múltiplos os parâmetros que podem causar a sua alteração química ou física (Chen, 1992). Por isso, na microencapsulação de fármacos peptídicos a es- 
colha do método é particularmente condicionada pela garantia da estabilidade do material a encapsular. É importante conhecer as alternativas disponíveis e a sua aplicabilidade na encapsulação dos fármacos peptídicos, conforme será revisto. Serão, ainda, apresentados exemplos de métodos de microencapsulação aplicáveis à administração oral de fármacos peptídicos. Numa terceira parte desta revisão (Silva et al., 2002a), os conceitos apresentados nas primeira e segunda partes, serão aplicados na administração oral da insulina, fármaco que devido à sua importante ação biológica e ao seu impacto social, é utilizado como referência.

\section{DEFINIÇÕES EM MICROENCAPSULAÇÃO}

As micropartículas são pequenas partículas sólidas e esféricas com tamanho que varia entre 1 e $1000 \mu \mathrm{m}$ (Arshady, 1991; Burgess, Hickey, 1994). Subdividem-se em microcápsulas, sistemas reservatório contendo a substância ativa revestida por polímeros de espessuras variáveis, que constituem a membrana da cápsula, e em microsferas, sistemas matriciais nos quais o fármaco se encontra uniformemente disperso e/ou dissolvido numa rede polimérica (Giunchedi, Conte, 1995; Kas, Oner, 2000). Pode-se fazer a distinção entre microcápsulas polinucleares e mononucleares conforme o núcleo esteja ou não dividido no interior da partícula revestida. As microesferas podem ser homogêneas ou heterogêneas conforme a substância ativa se encontre no estado molecular (dissolvido) ou na forma de partículas (suspenso) (Figura 1) (Aftabrouchad, Doelker, 1992).

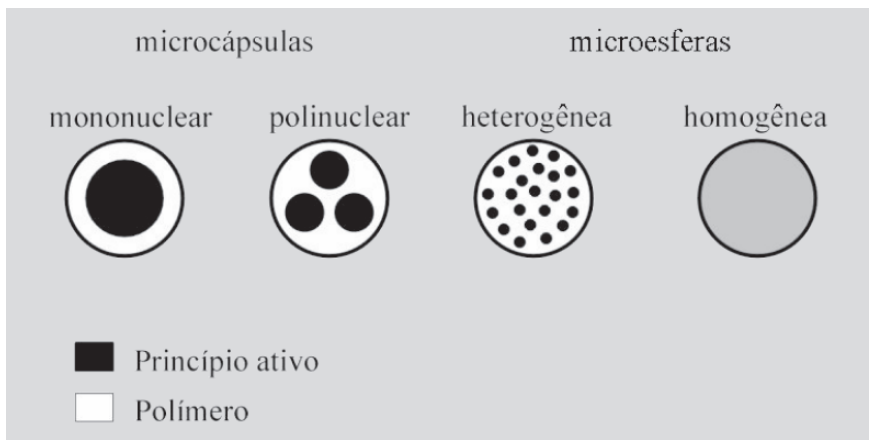

FIGURA 1 - Modelo da estrutura dos diferentes tipos de micropartículas (Adaptado de Aftabrouchad, Doelker, 1992).

A definição de micropartículas pode ser ampliada para incluir as nanopartículas, semelhantes às anteriores, mas com dimensões de 10 a $1000 \mathrm{~nm}$, caracterizando um sistema coloidal (Alléman, Gurny, Doelker, 1993). Outros dois sistemas que, por vezes, são incluídos na classificação das micropartículas são os lipossomas e as emulsões lipídicas, também conhecidos por microesferas lipídicas. Porém, estes sistemas não satisfazem a definição pelo fato de não serem sólidos: um é semi-sólido e outro é líquido (Burgess, Hickey, 1994).

A tecnologia da microencapsulação tem sido utilizada em diversas indústrias, como na agrícola, alimentar, de produtos domésticos, médica, gráfica e cosmética. $\mathrm{Na}$ indústria farmacêutica, as aplicações são muito variadas: mascararamento de sabores ou odores, conversão de líquidos em sólidos, proteção em relação aos agentes atmosféricos (umidade, luz, calor e/ou oxidação), redução ou eliminação da irritação gástrica ou efeitos secundários provocados por alguns fármacos, redução da volatilidade, administração de fármacos incompatíveis, melhoramento das características de escoamento de pós, facilitação do manuseio de substâncias tóxicas, auxilio à dispersão de substâncias insolúveis em água em meios aquosos e produção de formas farmacêuticas de liberação controlada, sustentada e vetorizada (Burgess, Hickey, 1994; Kas, Oner, 2000). As vantagens mais específicas são: liberação precisa de baixas doses de fármacos potentes, redução da concentração do fármaco em outros locais que não os órgãos ou tecidos alvo e proteção dos compostos lábeis, antes e depois da administração, até exercerem a sua ação farmacológica (Burgess, Hickey, 1994). As nanopartículas têm sido usadas como adjuvantes em vacinas e como formas de liberação para a administração parenteral de citostáticos e antibióticos, administração oral de corticosteróides e peptídeos e em aplicações oftálmicas (Couvreur, Dubernet, Puisieux, 1995; Kreuter, 1994).

O método ideal de microencapsulação deve ser simples, reprodutível, rápido, fácil de se transpor à escala industrial e deve ser pouco dependente das características de solubilidade do fármaco e polímero (Giunchedi, Conte, 1995).

\section{MÉTODOS GERAIS DE MICROENCAPSULAÇÃO}

Na Tabela I estão resumidos diferentes métodos de preparação de micro e nanopartículas.

\section{Técnicas de revestimento}

As técnicas de revestimento em microencapsulação incluem o revestimento clássico em turbina de drageamento, a centrifugação e a fluidização. No revestimento clássico, são empregadas turbinas de drageamento aquecidas, em que os fármacos de natureza sólida sofrem 
TABELA I - Métodos de preparação de micro e nanopartículas

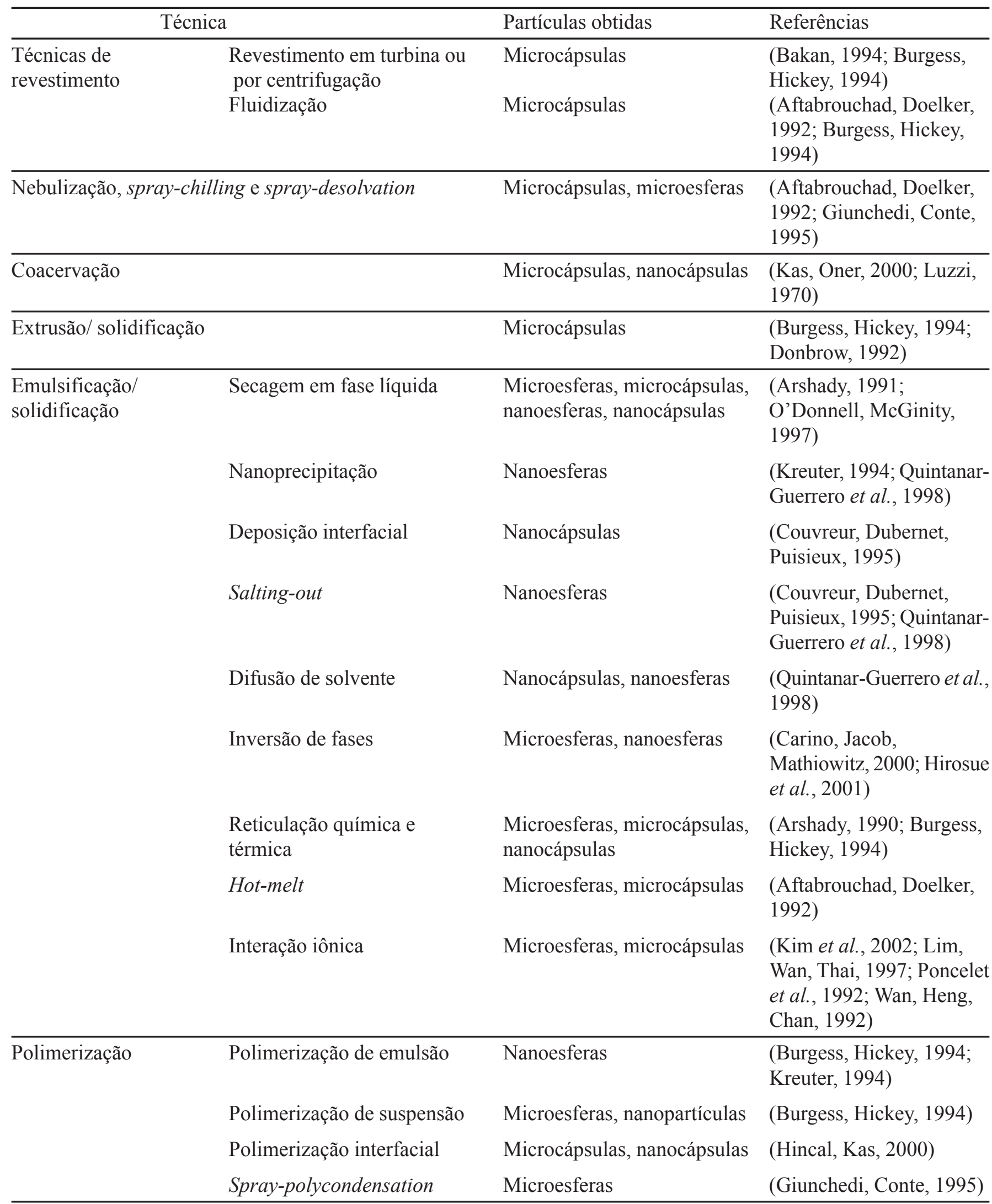


rotação e, sobre as quais, é nebulizado ou vertido o material de revestimento fundido ou dissolvido (Burgess, Hickey, 1994). No revestimento por centrifugação é utilizada uma força centrífuga para lançar as partículas do fármaco contra massas poliméricas presentes nos múltiplos orifícios de uma centrífuga rotativa. Os fármacos encapsulados formam microcápsulas embriônicas, que são, posteriormente, endurecidas pelo ar ou por um agente de endurecimento (Bakan, 1994). O revestimento de pequenas partículas permite um perfil de liberação mais adequado do que o dos comprimidos revestidos, além de que é possível obter vários lotes de micropartículas com diferentes espessuras de revestimento e misturá-los para obter diferentes perfis de liberação controlada (Burgess, Hickey, 1994).

Na fluidização ou processo de Wurster, as partículas sólidas de fármaco são suspensas numa corrente de ar quente ascendente formando um leito fluidizado. As partículas são revestidas por nebulização de uma solução do polímero, como éteres da celulose, pectina e polimetacrilatos. Esta técnica exige, normalmente, a utilização de uma quantidade importante de substância ativa, mas permite obter um revestimento de espessura mais uniforme do que o revestimento clássico. Podem surgir problemas com os solventes orgânicos inflamáveis pelo risco de explosão na câmara fluidizante (Aftabrouchad, Doelker, 1992; Burgess, Hickey, 1994).

\section{Nebulização, spray-chilling e spray-desolvation}

Na nebulização ou spray-drying, o fármaco é disperso ou dissolvido numa solução orgânica ou aquosa do polímero e o sistema é nebulizado numa corrente de ar quente. Após a evaporação do solvente, as micropartículas secas são recuperadas. É uma técnica simples, rápida, permitindo a obtenção da forma final sem ter que recorrer a lavagens para isolar as micropartículas ou eliminar resíduos de solventes. Tem como inconveniente o uso de calor, capaz de afetar as propriedades de polímeros e fármacos termo-sensíveis (Aftabrouchad, Doelker, 1992).

Por nebulização, podem se formar microcápsulas ou microesferas, conforme o fármaco está disperso ou dissolvido na solução de polímero. Os fatores de formulação que influenciam as características das micropartículas são a concentração em polímero, a temperatura e a velocidade de alimentação do sistema. A eficiência de encapsulação varia normalmente entre 70 e $85 \%$, independentemente dos parâmetros do processo (Giunchedi, Conte, 1995). Tanto os fármacos hidrossolúveis como lipossolúveis podem ser encapsulados, contudo, enquanto que a liberação dos primeiros apresenta frequentemente um burst effect inicial elevado, para os segundos a liberação tem uma cinética próxima de ordem zero. É vasta a gama de polímeros utilizados: poliésteres biodegradáveis, polianidridos, derivados da celulose, polímeros acrílicos, álcool polivinílico (PVA), polivinilpirrolidona (PVP), albumina, ceras, siloxanos e quitosanas. A técnica de nebulização permite obter elevada eficiência de encapsulação, o tempo de preparação é reduzido e é possível obter liberação gradual de fármaco. Entre as desvantagens da nebulização encontram-se o custo do equipamento e a dificuldade em obter partículas esféricas (Giunchedi, Conte, 1995). Outro inconveniente é a elevada formação de fibras devido a ligações intermoleculares entre as cadeias poliméricas e à incapacidade da força de nebulização em quebrar o líquido em gotas (Bodmeier, Chen, 1988).

De modo idêntico, na técnica de spray-chilling ou spray-congealing, o fármaco dissolvido ou disperso num veículo fundido é nebulizado, mas, neste caso, em uma corrente de ar frio, o que causa a solidificação do veículo e a formação das micropartículas. Tal como a nebulização, esta técnica é rápida e ocorre num só passo, além de que não envolve a utilização de água ou solventes orgânicos. Foram utilizados ésteres de ácidos graxos como materiais para a matriz (Giunchedi, Conte, 1995).

A técnica de spray-desolvation também utiliza um nebulizador. Baseia-se na solubilidade/miscibilidade do solvente do polímero num não-solvente. O solvente com o polímero dissolvido é nebulizado, sob a forma de gotas, para a superfície do não-solvente obtendo-se partículas sólidas. Deste modo não se utiliza o aquecimento para evaporação do solvente como na nebulização (spraydrying). Este método é aplicável a fármacos sensíveis ao calor, mesmo a baixas temperaturas ou por períodos curtos, como alguns peptídeos e proteínas, tendo sido utilizados como polímeros o PVA, ácido poliláctico (PLA) e ácido poli(láctico-co-glicólico) (PLGA) (Giunchedi, Conte, 1995).

\section{Coacervação}

A coacervação ou separação de fases consiste na obtenção, a partir de uma solução contendo uma macromolécula dispersa, de duas fases líquidas imiscíveis, uma fase de coacervado, em que a macromolécula está presente em elevada concentração e uma fase de equilíbrio, em que a mesma está em baixa concentração. Se apenas está presente uma única macromolécula este processo é designado por coacervação simples e quando estão presentes duas ou mais moléculas de carga oposta é referido como coacervação complexa. A coacervação simples é induzida por uma alte- 
ração de condições que causam a dessolvatação da macromolécula, como a adição de um não-solvente, a adição de micro-íons ou alterações da temperatura, que promovem as interações macromolécula-macromolécula em detrimento das interações macromolécula-solvente. Como exemplos temos a adição de álcool ou sulfato de sódio a uma solução aquosa de gelatina (Luzzi, 1970). A coacervação complexa é induzida através da criação de forças electrostáticas entre as macromoléculas, como por exemplo, nas interações gelatina-acácia, Carbopol ${ }^{\circledR}$-gelatina, pectina-gelatina, gelatina-gelatina e carboximetilcelulose sódica-gelatina (Burgess, Hickey, 1994). A deposição do coacervado em volta de pequenas partículas insolúveis no líquido de equilíbrio leva à formação de cápsulas embriônicas, que, após gelificação, originam as microcápsulas (Kas, Oner, 2000).

A coacervação em fase aquosa apenas pode ser usada para encapsular materiais insolúveis em água. A coacervação em fase orgânica permite a encapsulação de material hidrossolúvel, mas exige a utilização de solventes orgânicos (Kas, Oner, 2000).

Esta técnica é complexa, em termos operacionais, e necessita de controle minucioso das condições experimentais. Os problemas mais comuns são a aglomeração massiça a que as micropartículas são sujeitas e, no caso da manipulação em meios não-aquosos, os custos elevados relacionados com a reciclagem de não-solventes e eliminação de solventes residuais (Aftabrouchad, Doelker, 1992). Em alguns casos, é necessária a estabilização das microcápsulas recorrendo a temperatura elevada, valores de $\mathrm{pH}$ extremos ou agentes de reticulação, o que limita a encapsulação de materiais termo- e quimicamente lábeis como as proteínas e polipeptídeos (Burgess, Hickey, 1994). Apresenta a vantagem de permitir a obtenção de rendimentos elevados na encapsulação de fármacos hidrossolúveis (Aftabrouchad, Doelker, 1992).

A separação de fases em óleo pode ser utilizada na preparação de micropartículas de PLGA. Os fármacos hidrossolúveis são dissolvidos em água e dispersos na solução orgânica do polímero (emulsão A/O) e os fármacos hidrofóbicos podem ser dissolvidos ou dispersos na solução do polímero. Em seguida, é adicionado um não-sovente orgânico que induz a separação de fases (Jain, 2000).

\section{Extrusão/solidificação}

No método de extrusão, o material do núcleo na forma líquida, fundido ou em solução, é lançado através do orifício de um tubo fino ou seringa para formar microgotas, cujo tamanho será dependente do diâmetro do orifício e da velocidade de saída do material. As gotas contêm o mate- rial de revestimento ou este é adicionado quando as gotas caem ou são injetadas. A solidificação do material de revestimento pode ocorrer por evaporação do solvente, difusão do solvente ou reação química (Donbrow, 1992).

Este método tem sido aplicado na obtenção de micropartículas de alginato de cálcio, inicialmente desenvolvidas para a encapsulação de células vivas (Lim, Sun, 1980), já que o processo utilizado não envolve condições agressivas que possam ser nocivas para as células. O método baseia-se na gelificação ionotrópica do alginato e consiste em incorporar o material a encapsular numa solução de alginato de sódio, para depois a mistura sofrer extrusão gota a gota, através de uma pipeta de calibre reduzido ou de uma seringa, para uma solução de cloreto de cálcio (Burgess, Hickey, 1994; Kim, Lee, 1992). O alginato gelifica após ligação dos íons bivalentes de cálcio aos blocos de ácido gulurônico das cadeias de alginato constituindo o modelo da "caixa de ovos" (Gombotz, Wee, 1998). Sendo as partículas obtidas relativamente grandes, foram desenvolvidas variantes do método. Algumas destas consistem na utilização de um sistema de pressão para forçar a saída do alginato através da pipeta, um sistema de vibração para dispersar as gotas da extremidade da pipeta com o qual se obtiveram partículas com menos de $300 \mu \mathrm{m}$ e um método de nebulização que originou partículas com menos de $1 \mu \mathrm{m}$ (Burgess, Hickey, 1994). As gotas de gel podem ser reticuladas pela adição de poli(L-lisina) ou quitosana para diminuir a erosão da matriz de alginato e retardar a liberação do composto encapsulado (Lemoine et al., 1998; Murata et al., 1993). A preparação de microesferas de pectinato de cálcio também foi efectuada por este processo (Sriamornsak, 1998), em que o alginato foi substituído pela pectina.

\section{Emulsificação/solidificação}

Podem-se preparar micropartículas por formação prévia de uma emulsão, cuja fase interna, na forma de microgotas, é solidificada para originar as micropartículas (Donbrow, 1992). A emulsificação pode ser direta ou indireta, ocorrendo, neste caso, uma inversão de fases. Quando está presente a fase externa correta, o tamanho da gota pode ser reduzido para um valor desejado por intermédio de forças de dispersão. A solidificação pode ocorrer por processos muito variados a seguir descritos.

\section{Secagem em fase líquida}

O método de secagem em fase líquida, também designado método de evaporação de solvente ou de emulsificação/evaporação de solvente, envolve a preparação de uma solução orgânica do polímero contendo o 
fármaco dissolvido e a sua dispersão sob a forma de microgotas num meio de não-solvente (meio de suspensão), um líquido em que o polímero seja insolúvel, geralmente estabilizado com um agente de suspensão para manter a individualidade das gotas. Em seguida, ocorre a eliminação do solvente por evaporação (Arshady, 1991). O não-solvente deverá ter um ponto de ebulição superior ao do solvente orgânico e deverá ser imiscível com este (Aftabrouchad, Doelker, 1992). Aágua e o diclorometano são os não-solventes e solventes, respectivamente, mais utilizados. Podem ser utilizados diferentes tipos de emulsões, $\mathrm{O} / \mathrm{A}, \mathrm{A} / \mathrm{O}, \mathrm{A} / \mathrm{O} / \mathrm{A}$ ou $\mathrm{O} / \mathrm{A} / \mathrm{O}$. As emulsões $\mathrm{O} / \mathrm{A}$ são vantajosas porque utilizam a água como não-solvente, ou seja, o processo é econômico e não necessita de reciclagem, as partículas são fáceis de lavar e raramente aglomeram (Aftabrouchad, Doelker, 1992). A grande limitação é a sua utilização exclusiva para fármacos lipossolúveis, pelo que surgiram como alternativas a utilização de sistemas anidros do tipo $\mathrm{O} / \mathrm{O}$ e as emulsões múltiplas $\mathrm{A} / \mathrm{O} / \mathrm{A}, \mathrm{A} / \mathrm{O} / \mathrm{O}$ ou $\mathrm{A} / \mathrm{O} / \mathrm{O} / \mathrm{O}$, que permitem obter rendimentos de encapsulação de substâncias ativas hidrossolúveis mais elevados (O’Donnell, McGinity, 1997).

Na microencapsulação de proteínas utilizando emulsões múltiplas $\mathrm{A} / \mathrm{O} / \mathrm{A}$, em que os fármacos são dissolvidos na fase aquosa interna, existe uma tendência para a sua acumulação na interface solvente-água, ocorrendo freqüentemente, a sua desnaturação ou agregação (Sah, 1999). Para evitar este efeito, que pode alterar a sua atividade, foram desenvolvidos métodos não-aquosos, que utilizam um sistema do tipo sólido em óleo em água $(\mathrm{S} / \mathrm{O} /$ A) (Carrasquillo et al., 2001; Castellanos et al., 2001), em que a proteína no estado sólido é dispersa diretamente no solvente do polímero.

Os processos de secagem em fase líquida utilizam, muitas vezes, poliésteres biodegradáveis, como são os polímeros de hidroxiácidos, a saber, PLA, PLGA, ácido poliglicólico (PGA), poliidroxibutirato (PHB), policaprolactona (PCL), policarbonato de etileno (PEC), policarbonato de propileno (PPC) e poli(carbonato de etileno-cocarbonato de propileno) (PEPC) (Arshady, 1991). Também foi utilizado como polímero um homopolipeptídeo modificado com segmentos de polisssarcosina, que são solúveis quer em água, quer em solventes orgânicos (Kidchob, Kimura, Imanishi, 1996).

A granulometria das micropartículas pode ser controlada por vários parâmetros (viscosidade, velocidade de agitação e estabilizador de suspensão), podendo variar desde $100 \mathrm{~nm}$ a $2 \mathrm{~mm}$ (Arshady, 1991). A homogeneização da emulsão constitui uma etapa determinante para obter partículas submicrônicas, já que cada gota emul- sificada origina uma partícula de polímero. A ultrassonicação e os microfluidizadores permitem obter gotas com um tamanho inferior a 0,5 mm (Quintanar-Guerrero et al., 1998). Vários fatores influenciam a eficiência de encapsulação e a morfologia das micropartículas preparadas a partir de emulsões A/O/A, como, a estabilidade da emulsão primária (Schugens et al., 1994), a adição de tampões ou sais à fase aquosa interna ou externa (Herrmann, Bodmeier, 1995), a adição de tensoativos à emulsão primária (Soriano et al., 1995) e o volume de fase aquosa interna (Crotts, Park, 1995).

O solvente pode, ainda, ser eliminado recorrendo à liofilização e à nebulização (Aftabrouchad, Doelker, 1992).

Entre os aspectos mais importantes a considerar na produção em larga escala, por este método, encontram-se a escolha do solvente orgânico e a sua remoção do produto acabado (Arshady, 1991). A transposição à escala industrial é dificultada no caso das nanopartículas, devido à elevada energia que é necessário aplicar durante a homogeneização (Soppimath et al., 2001).

\section{Extração de solvente}

$\mathrm{Na}$ extração de solvente, o solvente do polímero é escolhido de forma a ser miscível com o não-solvente, por exemplo, acetona com água ou diclorometano com um óleo mineral, de forma que as gotas de polímero percam o solvente para o meio de suspensão para serem convertidas nas respectivas partículas sólidas (Arshady, 1991). A extração de solvente conduz à obtenção de micropartículas com melhores características (forma mais regular, tamanho inferior, menor variação na granulometria) do que a evaporação de solvente, porém a maior porosidade das partículas, devida à remoção mais rápida do solvente, aumenta a área superficial (maior porosidade), o que leva a um efeito burst na liberação de fármaco (Giunchedi, Conte, 1995).

Existem vários métodos baseados neste princípio, sobretudo na preparação de nanopartículas, como, a nanoprecipitação, a deposição interfacial, o salting-out, a difusão de solvente, a inversão de fases e a separação de fases.

A nanoprecipitação e a deposição interfacial são métodos idênticos baseados numa emulsificação espontânea da fase interna orgânica contendo o polímero dissolvido na fase externa aquosa, porém no primeiro caso são obtidas nanoesferas, enquanto que, no segundo caso, obtêmse nanocápsulas. Na nanoprecipitação, o polímero (por exemplo, PLA, PCL, PLGA) e o fármaco são dissolvidos num solvente de polaridade intermédia e miscível com a água, como a acetona ou o etanol. Esta fase é injetada ou 
vertida para uma solução aquosa contendo um agente estabilizador (por exemplo, álcool polivinílico ou poloxâmero 188), sob agitação. A deposição do polímero na interface entre a água e o solvente orgânico, causada por uma rápida difusão do solvente, leva à formação instantânea de uma suspensão coloidal (Kreuter, 1994; QuintanarGuerrero et al., 1998). Na deposição interfacial é introduzido um quinto componente, de natureza oleosa, miscível com o solvente do polímero, mas imiscível com a mistura de solvente/não-solvente. O polímero deposita-se na interface entre as gotas de óleo finamente dispersas e a fase aquosa dando origem a nanocápsulas (Couvreur, Dubernet, Puisieux, 1995). Contudo, a utilização de solvente orgânico aumenta o tamanho médio das partículas (Wehrle, Magenheim, Benita, 1995) e aumenta o risco de toxicidade. A dificuldade em escolher um sistema fármaco/polímero/ solvente/não-solvente, que permita obter uma eficiência de encapsulação adequada, constitui um inconveniente de ambos os métodos (Alléman, Gurny, Doelker, 1993). Por outro lado, é necessário um controle minucioso das condições operacionais e a encapsulação de fármacos hidrossolúveis não é eficiente (Kreuter, 1994; Quintanar-Guerrero et al., 1998). Na nanoprecipitação e na deposição interfacial utiliza-se solução aquosa como meio de dispersão e, por isso, designam-se por métodos de difusão de solvente em água (water solvent diffusion, WSD). Com o objetivo de melhorar a eficiência de encapsulação, sobretudo para fármacos hidrossolúveis, os métodos de WSD foram modificados originando o método de difusão de solvente em óleo (oil solvent diffusion, OSD), no qual o meio de dispersão era um óleo e a solução de polímero era constituída por PLGA, fármaco, acetona e metanol. Obtiveram-se nanoesferas e a eficiência de encapsulação da elcatonina, um peptídeo hidrofílico, foi de $44,5 \%$, comparativamente a um valor de 19,5\% obtido por utilização da água como meio de dispersão (Kawashima et al., 1998). Nos métodos de WSD, a emulsão é espontânea devido à rápida difusão do solvente na superfície das gotas, porém, no método de OSD, essa rápida difusão não ocorre sendo necessário adicionar um tensoativo à fase orgânica contendo o polímero (Takeuchi, Yamamoto, Kawashima, 2001).

Uma variante deste método baseia-se na separação de um solvente miscível na água, normalmente a acetona, a partir de soluções aquosas por um efeito de salting-out. $\mathrm{O}$ polímero e o fármaco são dissolvidos em acetona e esta solução é emulsificada mediante agitação mecânica num gel aquoso contendo um agente de salting-out (eletrólitos, como o cloreto de magnésio, cloreto de cálcio e acetato de magnésio ou não-eletrólitos, como a sacarose) e um estabilizador coloidal (álcool polivinílico, polivinilpirrolidona ou hidroxietilcelulose). A emulsão O/A formada é diluída num volume suficiente de água ou soluções aquosas para promover a difusão da acetona para a fase aquosa, induzindo a formação de nanopartículas. Esta técnica, utilizada na preparação de nanoesferas de PLA, polimetilmetacrilato e etilcelulose, permite encapsular elevadas quantidades de fármaco, origina rendimentos elevados, não requer temperaturas elevadas e é facilmente transposta à escala industrial. A grande desvantagem é a sua aplicação exclusiva a fármacos lipofílicos e as indispensáveis etapas de lavagem das partículas (Couvreur, Dubernet, Puisieux, 1995; Quintanar-Guerrero et al., 1998).

Uma variante do salting-out é a emulsificação/difusão de solvente, que consiste na dissolução do polímero de encapsulação (por exemplo, PLA) num solvente parcialmente solúvel em água (por exemplo, carbonato de propileno), saturado com água. Após emulsificação desta fase, sob agitação vigorosa, numa solução aquosa contendo um estabilizador, adiciona-se água ao sistema, o que provoca a difusão do solvente para a fase externa e a formação de nanoesferas ou nanocápsulas, de acordo com a razão óleo/polímero. O solvente é eliminado por evaporação ou filtração, de acordo com o seu ponto de ebulição. Este processo utiliza solventes orgânicos aceitáveis do ponto de vista farmacêutico, não necessita de passos de homogeneização, conduz a rendimentos elevados, é reprodutível e é facilmente transposto à escala industrial, porém só é eficaz na encapsulação de fármacos lipofílicos (Quintanar-Guerrero et al., 1998).

$\mathrm{Na}$ microencapsulação por inversão de fases, uma solução aquosa de fármaco é adicionada a uma solução orgânica diluída de polímero (por exemplo, diclorometano), para formar uma emulsão. Esta emulsão é adicionada rapidamente a uma grande quantidade de um nãosolvente (por exemplo, éter de petróleo), o que causa inversão de fases. As nanoesferas e microesferas formamse espontaneamente. Este método foi aplicado na obtenção de partículas de PLA e polianidridos (Carino, Jacob, Mathiowitz, 2000; Mathiowitz et al., 1997) e de PLGA (Hirosue et al., 2001).

\section{Reticulação química e térmica}

A solidificação das microgotas de uma emulsão por reticulação é freqüentemente utilizada, sobretudo na preparação de microesferas de albumina, mas também foi usada na preparação de microcápsulas de hemoglobina e nanocápsulas de fibrinogêneo, albumina, gelatina e polissacarídeos (Arshady, 1990). A emulsificação da macromolécula numa fase oleosa, com obtenção de uma emulsão $\mathrm{A} / \mathrm{O}$, leva à formação de gotas que sofrem reticulação covalente por ação do calor $\left(>50^{\circ} \mathrm{C}\right)$ ou por adição de um agente de reticulação químico (por exemplo, 
glutaraldeído) (Burgess, Hickey, 1994). Para manter a individualidade das gotas durante o processo de reticulação pode ser necessário adicionar um agente de suspensão/estabilizador ou um inibidor da coagulação (Arshady, 1990). A utilização de calor e de agentes de reticulação, com potencial toxicidade, são fortes limitações na aplicação deste método à encapsulação de fármacos peptídicos.

\section{Hot-melt}

No método de hot-melt ocorre a transformação, por arrefecimento, de gotas poliméricas fundidas, obtidas por emulsificação, em micropartículas sólidas. Este método tem sido aplicado na preparação de microesferas de polianidridos. As vantagens do processo residem na não utilização de solventes orgânicos, no entanto, a sua aplicação limita-se a polímeros e substâncias ativas termoestáveis (Aftabrouchad, Doelker, 1992).

\section{Interação iônica}

Alternativamente ao método de extrusão, pode recorrer-se a uma técnica de emulsificação para obter micropartículas de alginato de cálcio, segundo a qual uma solução aquosa de alginato de sódio é dispersa numa fase imiscível e as gotas de gel formadas reagem com íons de cálcio, que são adicionados à fase externa, formando-se microesferas. É possível obter rendimento elevado de encapsulação de fármacos hidrofílicos e partículas com tamanho inferior a $150 \mu \mathrm{m}$ (Wan, Heng, Chan, 1992). Este método foi adaptado para obtenção de microesferas de quitosana, tendo a gelificação sido induzida por $\mathrm{NaOH}$ 1 M (Lim, Wan, Thai, 1997), condições demasiado drásticas para a maioria dos fármacos bioativos. Por esta razão, a utilização de $\mathrm{NaOH}$ foi, posteriormente, substituída pela utilização de aniôns multivalentes, como, tripolifosfato, citrato e sulfato para reticular a quitosana emulsificada (Shu, Zhu, 2001).

Também é possível obter micropartículas de alginato de cálcio por emulsificação/gelificação interna. $\mathrm{O}$ cálcio é disperso sob a forma de um sal insolúvel (por exemplo, carbonato de cálcio) na solução de alginato de sódio. Esta mistura é emulsificada numa fase oleosa para obtenção de uma emulsão A/O e o cálcio presente na fase interna é liberado por acidificação da fase oleosa externa causando a gelificação do alginato (Poncelet et al., 1992). Este método foi aplicado na encapsulação de fármacos lipofílicos utilizando uma emulsão $\mathrm{O} / \mathrm{A} / \mathrm{O}$, sendo passível de ser transposto à escala industrial (Ribeiro et al., 1999).

Recentemente, foi desenvolvido um método baseado na formação de uma emulsão água em silicone contendo um polímero catiônico, o poliquaternio-24, na fase aquosa (Kim et al., 2002). Esta emulsão foi dispersa numa solução de laurilsulfato de sódio, um tensoativo aniônico, que complexa com o polímero catiônico, solidificando as gotas da fase aquosa para conduzir à formação de micropartículas. Este método é vantajoso porque não utiliza solventes orgânicos, nem agentes de reticulação tóxicos.

\section{Polimerização}

Existem diversas técnicas de polimerização. A polimerização in situ em sistema emulsionado é um método muito rápido, facilmente transponível à escala industrial (Kreuter, 1994). O monômero é dissolvido na fase externa de uma emulsão, normalmente uma solução aquosa, na qual está presente um iniciador e um tensoativo numa concentração superior à concentração necessária para a formação de micelas. A polimerização ocorre no interior hidrofóbico das micelas de tensoativo o qual o monômero e o iniciador se difundem. As partículas obtidas são muito pequenas, mas, normalmente, têm elevadas concentrações de monômero associado (Burgess, Hickey, 1994). O fármaco pode estar presente durante a polimerização para ser aprisionado na rede polimérica, pode estar ligado covalentemente ao polímero ou pode ser adicionado após a polimerização para ser adsorvido à superfície do polímero (Kreuter, 1994). A polimerização de emulsão em fase externa orgânica não é tão utilizada porque requer elevadas quantidades de solventes orgânicos e tensoativos e também pela natureza tóxica dos monômeros utilizados (Kreuter, 1994). O método foi empregado para obter nanoesferas de poliacrilamida, polialquilcianoacrilato e polimetilmetacrilato (Alléman, Gurny, Doelker, 1993). Também se utilizou este método para obter microesferas de polímeros acrílicos termossensíveis (Ichikawa, Fukumori, 1997).

Na polimerização in situ em sistema suspenso, um monômero líquido insolúvel em água e o fármaco são dispersos numa fase aquosa, que pode conter um iniciador e estabilizadores. O polímero forma-se por reação entre os grupos funcionais de monômero, podendo, no entanto, ocorrer agregação. Por outro lado, a eliminação dos estabilizadores e aditivos usados para prevenir a coalescência do produto final é difícil de realizar. Por este método foram obtidas partículas de poli(2-hidroxietilmetacrilato) (Burgess, Hickey, 1994).

A polimerização in situ interfacial caracteriza-se pela polimerização de um monômero na interface de duas fases imiscíveis. Se a fase interna for um líquido, é possível dispersar ou solubilizar o monômero nesta fase e emulsionar a mistura na fase externa à qual se adiciona um co-reagente, que inicia a formação de polímero na super- 
fície das gotas de líquido. A sua utilização é limitada pela toxicidade associada aos monômeros que não reagem, pela elevada permeabilidade do revestimento e pela fragilidade das membranas obtidas. No entanto, é possível obter partículas com tamanho e espessura de parede controláveis por utilização de diferentes monômeros. O método conduziu à obtenção de partículas de polialquilcianoacrilato, poli(Na,Ne-L-lisinoediltereftalamida), poliamidas, polifenilésteres e poliuretanos (Hincal, Kas, 2000).

A spray-polycondensation envolve a condensação de um monômero hidrossolúvel reativo e a formação do produto numa única etapa. A polimerização ocorre por nebulização de uma solução ou dispersão do material do núcleo com monômeros e catalizador (Giunchedi, Conte, 1995).

\section{APLICAÇÃO DA MICROENCAPSULAÇÃO À ADMINISTRAÇÃO ORAL DE PEPTÍDEOS E PROTEÍNAS}

A Tabela II apresenta exemplos de microencapsulação de proteínas e peptídeos destinados a serem administrados pela via oral. Nos casos em que não é explícita a aplicação oral da formulação, é feita referência das suas potencialidades. Os estudos relativos à microencapsulação da insulina serão enfocados numa terceira parte desta revisão (Silva et al., 2002a).

\section{Poliésteres biodegradáveis}

Os polímeros de PLGA têm sido extensivamente empregados na encapsulação de peptídeos e proteínas pela sua excelente biocompatibilidade celular, biodegradabilidade e aprovação regulamentar (Jain, 2000). A utilização do PLGA como veículo de antígenos para imunização oral (Alpar, Eyles, Williamson, 1998), bem como na preparação de micropartículas contendo proteínas com o objetivo de obter formulações de liberação sustentada para administração parenteral (Castellanos et al., 2001; Jain, 2000; Putney, Burke, 1998) é muito freqüente, porém os estudos destinados à administração oral de fármacos peptídicos bioativos não são tão numerosos.

A microencapsulação da albumina sérica bovina (BSA) (Conway, Alpar, 1996; Rafati et al., 1997) e de um polipeptídeo de 33 aminoácidos (Blanco-Prieto et al., 1998), em microesferas de PLGA, pelo método de secagem em fase líquida, recorrendo a emulsão múltipla, permitiu obter diferentes eficiências de encapsulação e perfis de liberação em pH 7,4, de acordo com as condições experimentais. A eficiência de encapsulação máxima ob- tida foi de 96\% (Rafati et al., 1997) e por aumento da hidrofobicidade da superfície da partícula foi reduzido o burst effect inicial e a quantidade de proteína liberada (Conway, Alpar, 1996). A concentração de agente de estabilização (PVA), a concentração de PLGA e a homogeneização são condições críticas (Rafati et al., 1997). A microencapsulação de um peptídeo de 7 aminoácidos (Blanco-Prieto et al., 1998) levou à obtenção de baixas eficiências de encapsulação e a liberação in vitro quase imediata, pelo fato de a emulsão primária não ser suficientemente estável para que o peptídeo fique retido na fase interna. Este contato do peptídeo com a fase aquosa externa exigiu o desenvolvimento de estratégias eficazes, especificamente, a adição de um agente de estabilização (ovalbumina) à fase aquosa interna da emulsão múltipla e, tendo em consideração a solubilidade do peptídeo, a fase aquosa interna foi mantida em $\mathrm{pH}$ básico, em que o peptídeo é solúvel, enquanto que a fase aquosa externa foi mantida ácida.

A microencapsulação da ovalbumina em PLGA utilizando o método da emulsificação múltipla/evaporação de solvente permitiu obter eficiências de encapsulação de $40 \%$, sendo que $50 \%$ do fármaco ficou localizado na superfície das micropartículas, que apresentaram tamanho inferior a $2 \mathrm{~mm}$ (Takahata et al., 1998). Por incubação, durante duas horas, em meios gástrico e intestinal artificiais, a ovalbumina encapsulada resistiu à degradação proteolítica, porém a proteína à superfície foi rapidamente degradada pela tripsina e pela pepsina. No entanto, o microambiente ácido que é criado nas micropartículas incubadas em tampão fosfato salino a $37^{\circ} \mathrm{C}$ é capaz de produzir degradação significativa da proteína encapsulada ao fim de 7 dias, apesar do meio externo apresentar $\mathrm{pH}$ constante.

Os métodos de OSD, WSD e separação de fases em óleo foram utilizados na obtenção de nanoesferas de PLGA para encapsulação do hormônio liberador de tirotropina (TRH) e de elcatonina, dois peptídeos hidrossolúveis (Kawashima et al., 1998). O rendimento e a eficiência de encapsulação do fármaco nas nanoesferas foram superiores pelo método de OSD em relação aos outros dois métodos, para ambos os peptídeos. A OSD e a WSD foram, posteriormente, aplicadas na preparação de nanoesferas de elcatonina, revestidas com quitosana, um polímero mucoadesivo, para serem administradas intragastricamente a ratos (Kawashima et al., 2000). A ação fisiológica do peptídeo, ou seja, a redução do nível de cálcio no sangue, foi monitorizada, verificando-se que as nanoesferas revestidas com quitosana reduziram significativamente os níveis de calcemia comparativamente a uma solução de elcatonina e às nanoesferas não-revestidas. Essa redução foi prolongada por um período de 48 horas. 
TABELA II - Microencapsulação de peptídeos e proteínas para administração oral

\begin{tabular}{|c|c|c|c|c|}
\hline Polímero & Sistema & $\begin{array}{l}\text { Peptídeo ou } \\
\text { proteína }\end{array}$ & Técnica & Referência(s) \\
\hline \multicolumn{5}{|c|}{ Poliésteres biodegradáveis } \\
\hline \multirow[t]{4}{*}{ PLGA } & Microesferas & BSA & Evaporação de solvente & (Rafati et al., 1997) \\
\hline & Micropartículas & Ovalbumina & Evaporação de solvente & (Takahata et al., 1998) \\
\hline & Nanoesferas & Elcatonina & OSD & (Kawashima et al., 2000) \\
\hline & Nanopartículas & $\begin{array}{l}\text { Lisozima } \\
\text { gamainterferona }\end{array}$ & OSD & (Yoo, Choi, Park, 2001) \\
\hline \multirow[t]{4}{*}{ PLA } & Microesferas & Interferon-g & Evaporação de solvente & (Eyles et al., 1997) \\
\hline & Microcápsulas & Insulina & Evaporação de solvente & (Ma et al., 2000) \\
\hline & Nanoesferas & Insulina & Inversão de fases & $\begin{array}{l}\text { (Carino, Jacob, } \\
\text { Mathiowitz, 2000) }\end{array}$ \\
\hline & Microesferas & $\begin{array}{l}\text { Mesilato de } \\
\text { camostato }\end{array}$ & Evaporação de solvente & $\begin{array}{l}\text { (Uchida, Yasuda, } \\
\text { Matsuyama, 2001) }\end{array}$ \\
\hline \multicolumn{5}{|l|}{ Polímeros acrílicos } \\
\hline \multirow[t]{2}{*}{ Eudragit ${ }^{2}$} & Microesferas & Insulina & Emulsificação/solidificação & (Morishita et al., 1993) \\
\hline & Micropartículas & Insulina & Extração de solvente & $\begin{array}{l}\text { (Agarwal, Reddy, Khan, } \\
\text { 2001) }\end{array}$ \\
\hline Poli(2-HEMA) & Microesferas & $\begin{array}{l}\text { Derivado da } \\
\text { vasopressina }\end{array}$ & $\begin{array}{l}\text { Polimerização de } \\
\text { suspensão }\end{array}$ & (Lehr et al., 1992) \\
\hline \multirow[t]{2}{*}{$\begin{array}{l}\text { Poli(NIPAAm-co- } \\
\text { BMA-co-AA) }\end{array}$} & Micropartículas & Insulina & $\begin{array}{l}\text { Emulsificação/ } \\
\text { solidificação }\end{array}$ & $\begin{array}{l}\text { (Ramkissoon-Ganorkar et } \\
\text { al., 1999) }\end{array}$ \\
\hline & Micropartículas & Calcitonina & $\begin{array}{l}\text { Emulsificação/ } \\
\text { solidificação }\end{array}$ & $\begin{array}{l}\text { (Serres, Baudys, Kim, } \\
\text { 1996) }\end{array}$ \\
\hline \multirow[t]{5}{*}{ PIBCA } & Nanocápsulas & Insulina & Polimerização interfacial & (Damge et al., 1990) \\
\hline & Nanoesferas & Insulina & Polimerização de emulsão & (Damge et al., 1997b) \\
\hline & Nanoesferas & Insulina & Polimerização & (Radwan, 2001) \\
\hline & Nanocápsulas & Calcitonina & Polimerização interfacial & (Lowe, Temple, 1994) \\
\hline & Nanocápsulas & Octreotídeo & Polimerização interfacial & (Damge et al., 1997a) \\
\hline Poliacrilamida & Nanoesferas & Calcitonina & $\begin{array}{l}\text { Polimerização de } \\
\text { microemulsão inversa }\end{array}$ & (Lowe, Temple, 1994) \\
\hline \multicolumn{5}{|l|}{ Polímeros naturais } \\
\hline \multirow[t]{2}{*}{ Alginato } & Microesferas & BSA & Emulsificação/gelificação & (Lemoine et al., 1998) \\
\hline & Microesferas & TGF $-\beta_{1}$ & Extrusão/gelificação & (Mumper et al., 1994) \\
\hline Quitosana & Microcápsulas & Insulina & Reticulação química & (Aiedeh et al., 1997) \\
\hline \multirow[t]{3}{*}{ Alginato-Quitosana } & Micropartículas & BSA & Extrusão/gelificação & $\begin{array}{l}\text { (Coppi et al., 2001; } \\
\text { Okhamafe et al., 1996; } \\
\text { Polk et al., 1994; } \\
\text { Vandenberg et al., 2001) }\end{array}$ \\
\hline & Micropartículas & BSA & Nebulização/gelificação & (Coppi et al., 2001) \\
\hline & Micropartículas & Insulina & Extrusão/gelificação & (Ramadas et al., 2000) \\
\hline $\begin{array}{l}\text { Alginato-Quitosana- } \\
\text { PEG }\end{array}$ & Microcápsulas & Hirudina & Extrusão/gelificação & $\begin{array}{l}\text { (Chandy, Mooradian, Rao, } \\
\text { 1998) }\end{array}$ \\
\hline Quitosana-celulose & Micropartículas & BSA & Evaporação de solvente & $\begin{array}{l}\text { (Remunan-Lopez et al., } \\
\text { 1998) }\end{array}$ \\
\hline Gelatina & Microesferas & Ovalbumina & Reticulação química & (Nakamura et al., 1998) \\
\hline Amido/BSA & Microcápsulas & Aprotinina & $\begin{array}{l}\text { Emulsificação/reticulação } \\
\text { química }\end{array}$ & (Larionova et al., 1999) \\
\hline
\end{tabular}


TABELA II - continuação

\begin{tabular}{lllll}
\hline Polímero & Sistema & $\begin{array}{l}\text { Peptídeo ou } \\
\text { proteína }\end{array}$ & Técnica & Referência(s) \\
\hline i-Carragenano & Micropartículas & Peroxidase & Extrusão/interação iônica & (Patil, Speaker, 2000) \\
\hline Insulina & Nanoesferas & Insulina & Reticulação química & (Oppenheim et al., 1982) \\
\hline Álcool polivinílico & Microesferas & Insulina & Emulsificação/congelação & (Kimura et al., 1996) \\
\hline $\begin{array}{l}\text { Co-polímeros } \\
\text { P(MAA-g-EG) }\end{array}$ & Micropartículas & Insulina & Polimerização de suspensão (Lowman et al., 1999) \\
P(FA:PLGA) & Nanoesferas & Insulina & Inversão de fases & (Carino, Jacob, \\
& & & & Mathiowitz, 2000; \\
& & & Mathiowitz et al., 1997) \\
Graft-coPolymers & Nanopartículas & Calcitonina & Polimerização & (Sakuma et al., 1997) \\
Sistema CPP & Nanopartículas & LHRH & Polimerização & (Hillery et al., 1996) \\
\hline
\end{tabular}

PLGA - ácido poli(láctico-co-glicólico); BSA - albumina sérica bovina; OSD - difusão de solvente em óleo; PLA - ácido poliláctico; HEMA - hidroxietilmetacrilato; NIPAAm - N-isopropilacrilamida; BMA - butilmetacrilato; AA - ácido acrílico; PIBCA - poli(isobutilcianoacrilato); TGF - fator de crescimento transformante; PEG - polietilenoglicol; MAA$\gamma$-EG - co-polímero de ácido metacrílico e etilenoglicol; FA - anidrido fumárico; CPP - peptídeo co-polimerizado; LHRH - hormônio de liberação do hormônio luteinizante

Quando se utilizam os métodos de emulsão espontânea/difusão de solvente, a proteína deve estar dissolvida em solventes miscíveis com a água, como a acetona e o dimetilsulfóxido. A dissolução direta das proteínas em solventes orgânicos polares é possível, por exemplo, por emparelhamento iônico hidrofóbico, no qual os grupos carregados das proteínas interagem ionicamente com um grupo carregado de um agente tensoativo, obtendo-se proteínas modificadas menos hidrossolúveis e com maior solubilidade em solventes orgânicos. Esta estratégia foi adotada na nanoencapsulação de um complexo de lisozima (proteína) e oleato de sódio (agente hidrofóbico de emparelhamento iônico) em PLGA, pelo método de emulsão espontânea/difusão de solvente. A eficiência de encapsulação aproximou-se dos $100 \%$, apresentando-se como promissora na administração oral de proteínas (Yoo, Choi, Park, 2001).

A gamainterferona foi encapsulada, em microesferas de PLA, um poliéster biocompatível e biodegradável, por um método de emulsão múltipla/evaporação de solvente. As microesferas preparadas com quantidade reduzida de proteína apresentaram menor diâmetro em relação a outras preparadas com maior concentração de proteína. O processo de microencapsulação promoveu aumento da biodisponibilidade oral da proteína, já que a distribuição sistêmica, após a sua administração oral, foi significativamente superior para o gamainterferona encapsulada, em relação à não-encapsulada, (Eyles et al., 1997).
O inibidor proteolítico mesilato de camostato foi encapsulado em microesferas de PLA preparadas pelo método de emulsificação múltipla/evaporação de solvente, tendo, posteriormente, sido revestidas com acetato succinato de hidroxipropilmetilcelulose, um polímero entérico (Uchida, Yasuda, Matsuyama, 2001). A eficiência de encapsulação foi próxima de $80 \%$. A liberação em $\mathrm{pH}$ 6,8 foi rápida, já que todo o fármaco foi liberado em 45 minutos, enquanto que em $\mathrm{pH}$ 1,2, a liberação foi extremamente lenta, o que confirma a obtenção de uma formulação entérica.

\section{Polímeros acrílicos}

Foram preparadas microesferas de poli(2-hidroxietilmetacrilato) (poli-(2-HEMA)), por polimerização em suspensão, contendo 9-desglicinamida-8-argininavasopressina como peptídeo modelo. Estudou-se o efeito do revestimento com polycarbophil, um polímero mucoadesivo, na absorção intestinal do peptídeo. As propriedades mucoadesivas, promotoras da absorção e inibidoras da degradação proteolítica do polímero, permitiram um ligeiro aumento da absorção intestinal in vitro, mas nos resultados obtidos com os ensaios in situ e in vivo não se confirmou o efeito anterior (Lehr et al., 1992).

Foi utilizado um polímero sensível ao $\mathrm{pH}$ e à temperatura na encapsulação da calcitonina humana por um método de emulsificação/solidificação (Serres, Baudys, 
Kim, 1996). O polímero, produzido a partir de $N$ isopropilacrilamida (NIPAAm), butilmetacrilato (BMA) e ácido acrílico (AA), impede a solubilização das micropartículas em $\mathrm{pH}$ ácido e a $37{ }^{\circ} \mathrm{C}$, protegendo o fármaco da degradação gástrica, porém a $\mathrm{pH}$ neutro solubiliza-se liberando o fármaco no intestino. Obteve-se elevada eficiência de encapsulação da calcitonina e liberação rápida em pH 7,4 e em pH 4,5. Após contato prolongado com o polímero, a calcitonina permanecia bioativa e sem sofrer agregação.

A calcitonina também foi encapsulada em nanocápsulas de poli(isobutilcianoacrilato) (PIBCA), pelo método da polimerização interfacial (Lowe, Temple, 1994). A eficiência de microencapsulação foi de $90 \%$ e observouse maior resistência à degradação proteolítica em comparação com o peptídeo livre, porém a absorção intestinal não sofreu aumento significativo. No mesmo estudo, a calcitonina foi encapsulada em nanopartículas de poliacrilamida obtidas por polimerização duma microemulsão $\mathrm{A} / \mathrm{O}$. O monômero e o fármaco foram adicionados a um solvente orgânico contendo tensoativo, formando-se microemulsão, a qual após radiação UV, levou à polimerização do monômero. A eficiência de encapsulação atingiu os $23 \%$ e o peptídeo foi liberado imediatamente após re-hidratação, revelando incapacidade de proteção contra a degradação proteolítica.

O octreotídeo, um análogo da somatostatina, também foi encapsulado em PIBCA por polimerização interfacial (Damge et al., 1997a). A eficiência de encapsulação foi de aproximadamente $60 \%$ e o tamanho das nanocápsulas obtidas foi de $260 \mathrm{~nm}$. Os resultados obtidos revelaram aumento da atividade biológica do fármaco administrado, numa relação dose-efeito.

\section{Polímeros naturais}

Microesferas de alginato têm-se mostrado promissoras como sistema de liberação controlada de fármacos macromoleculares, tais como, vacinas (Bowersock et al., 1996; Cho et al., 1998) e polipeptídeos (Kim, Lee, 1992). $\mathrm{O}$ uso do alginato na preparação de microesferas contendo antígenos tem como objetivo a obtenção de partículas com menos de $10 \mathrm{~mm}$, para serem captadas pelas células M do tecido linfóide local. Como o método clássico de gelificação ionotrópica não permite a obtenção de partículas de diâmetro tão pequeno, outras técnicas têm sido abordadas. A BSA foi encapsulada em microesferas de alginato (Lemoine et al., 1998), pelo método de emulsificação/gelificação (Wan, Heng, Chan, 1992). As microesferas apresentaram diâmetro médio de $8 \mu \mathrm{m}$ e a eficiência de microencapsulação e o rendimento de encapsulação em proteína foram elevados $(>90 \%$ e $10 \% \mathrm{~m} / \mathrm{m}$, respectivamente). Quando as microesferas foram colocadas em tampão fosfato salino, a liberação do fármaco foi rápida, diminuindo após a reticulação prévia com poli(L-lisina) ou pela utilização de alginato de maior MM (Lemoine et al., 1998). O alginato também foi utilizado para encapsular o TGF- $\beta_{1}$ (transforming growth factor- $\beta_{1}$ ), um fármaco protéico de $25 \mathrm{KDa}$, utilizado para proteger o epitélio intestinal, o seu local de ação (Mumper et al., 1994). As microesferas, preparadas por extrusão, foram capazes de proteger a proteína das condições agressivas do estômago e liberá-lo no intestino delgado. A eficiência de encapsulação e o percentual de fármaco liberado foram próximos de $100 \%$. Devido a elevada afinidade da proteína para o alginato foi necessário recorrer a estratégias apropriadas, especificamente, tratamento das partículas com ácido e/ou incorporação de ácido poliacrílico, para assegurar a sua bioatividade.

A quitosana, um polímero catiônico, tem a capacidade de reagir com o alginato, originando a formação de gel. O complexo alginato-quitosana estabiliza o gel de alginato e reduz a sua porosidade (Coppi et al., 2001). Foram utilizadas 3 variantes da técnica de extrusão na preparação de microcápsulas de alginato-quitosana contendo BSA: gerador de gotas do tipo air-Jet (Polk et al., 1994; Vandenberg et al., 2001), gerador eletrostático de gotas (Okhamafe et al., 1996) e nebulização (Coppi et al., 2001). Quando se utiliza a técnica de nebulização é possível obter partículas com diâmetro médio inferior a $10 \mu \mathrm{m}$ e eficiência de encapsulação elevada (Coppi et al., 2001). Verificou-se que os fatores que influenciam o perfil de liberação da albumina são a concentração e MM da quitosana, a concentração de alginato, o tempo de reação alginato-quitosana e o pH da solução de quitosana (Polk et al., 1994). No trabalho de Okhamafe e colaboradores (1996), concluiu-se que as micropartículas de alginato-quitosana mostravam propriedades inadequadas de liberação da albumina a pH 1,2, com liberação de $80 \%$ e $94 \%$ às 4 e 24 horas, respectivamente, porém este resultado foi contestado por outros autores (Hari, Sharma, 1998). As microcápsulas de alginato revestidas com quitosana permitiram obter eficiências de encapsulação de BSA superiores a $95 \%$ e estabilidade em pH ácido, com liberação da proteína, em mais de $90 \%$, após transferência para valores de $\mathrm{pH}$ neutros (Vandenberg et al., 2001), mostrando-se adequadas para a administração oral de fármacos peptídicos.

A hirudina foi incorporada em microcápsulas de alginato preparadas por extrusão e revestidas com quitosana (Chandy, Mooradian, Rao, 1998). As microcápsulas de alginato-quitosana obtidas foram, posteriormente, revestidas com PEG tendo-se obtido tamanhos de 
900-1 $000 \mu \mathrm{m}$. A presença de PEG diminuiu a liberação a pH 7,4, já que na sua ausência $96 \%$ do fármaco tinha sido liberado em 48 horas, comparativamente com $86 \%$ na sua presença. $\mathrm{O}$ tratamento ácido das micropartículas $(0,1 \mathrm{M}$ $\mathrm{HCl}, 4$ horas) aumentou a liberação em $\mathrm{pH} 7,4$, atingindo $100 \%$ ao fim de 6 horas para as micropartículas revestidas com PEG, enquanto que na ausência de tratamento ácido a liberação, nesse período de tempo, foi de, aproximadamente, $70 \%$. A BSA foi encapsulada nas mesmas condições, tendo-se verificado que baixas concentrações de PEG $(0,05 \%)$ diminuem a liberação de proteína, embora as concentrações elevadas $(0,3 \%)$ aumentem a sua liberação. As propriedades anticoagulantes da hirudina são superiores com as micropartículas revestidas com PEG do que com as não-revestidas.

Para evitar a reticulação covalente da quitosana e melhorar as propriedades de liberação do polímero, foram desenvolvidas micropartículas de BSA por emulsão múltipla A/O/A seguida de evaporação de solvente, constituídas por um revestimento de polímero celulósico contendo no seu interior micronúcleos de quitosana (fase aquosa interna) nos quais a proteína está dissolvida. Estas partículas foram submetidas a liofilização. Independentemente do tipo de quitosana ou da razão quitosana/revestimento, o tamanho das partículas foi sempre inferior a $70 \mu \mathrm{m}$. A eficiência de microencapsulação foi elevada e, controlando as condições operacionais, é possível modular a liberação in vitro do fármaco (Remunan-Lopez et al., 1998).

A ovalbumina foi encapsulada em microesferas de gelatina por reticulação com glutaraldeído. As maiores eficiências de encapsulação (55 a 65\%) foram obtidas quando se utilizou solução de gelatina a $10 \%(\mathrm{~m} / \mathrm{v})$. A estabilidade das microesferas contra a degradação enzimática e o perfil de liberação da ovalbumina dependem da concentração da solução de gelatina e da quantidade de glutaraldeído (Nakamura et al., 1998).

Foram preparadas microcápsulas de amido e BSA por um método de emulsificação/reticulação química com cloreto de tereftaloíla nas quais foi incorporada, aprotinina, um inibidor enzimático de algumas proteases intestinais, como por exemplo a tripsina (Larionova et al., 1999). Para proteger o inibidor enzimático da acilação pelo agente de reticulação, os seus grupos amina foram protegidos com anidrido citracônico. Este sistema permitiu que a BSA fosse detectada no estado nativo, após 3 horas num meio contendo $\alpha$-amilase e tripsina, enquanto que na ausência de aprotinina ocorreu a degradação tripsínica total da proteína. Fatores como o tamanho das partículas, o tratamento com tampão alcalino seguido de incubação em pH 2,0, a densidade da reticulação e a presença de BSA influenciaram o perfil de liberação da aprotinina.
O i-carragenano, um polímero aniônico, foi utilizado na preparação de micropartículas contendo a enzima peroxidase de rabanete (Patil, Speaker, 2000). A enzima foi adicionada à solução aquosa de polímero e a mistura foi sujeita a extrusão para solução de oligoaminas que interagem com o carragenano para formar as micropartículas. Dependendo da amina utilizada, a eficiência de encapsulação variou entre 1 e $72 \%$. O processo de encapsulação não alterou a conformação estrutural ou a atividade específica da enzima. A liberação em $\mathrm{pH}$ 7,2 foi rápida, $98 \%$ em 100 minutos, o que se deveu à estrutura porosa da matriz e à baixa massa molecular da proteína.

\section{Co-polímeros}

As nanopartículas compostas por graft-coPolymers com estrutura central hidrofóbica e ramificações hidrofílicas são úteis como veículos para fármacos hidrofílicos. A calcitonina foi encapsulada em nanopartículas compostas por diferentes polímeros hidrofílicos na superfície: ácido polimetacrílico (polianiônico e sensível ao $\mathrm{pH}$ ), poli $(\mathrm{N}$ isopropilacrilamida) (termossensível, não iônico) e poli( $N$-vinilacetamina $)$, poli( $N$-vinilacetamida-covinilamina) e polivinilamina (catiônicos). A eficiência de microencapsulação da calcitonina foi elevada, embora dependente da estrutura das ramificações hidrofílicas. A formulação mostrou-se adequada não só na incorporação de fármacos peptídicos hidrossolúveis como também na promoção da absorção pelo trato GI (Sakuma et al., 1997).

\section{Sistemas conjugados de peptídeo co-polimerizado (CPP)}

Uma nova abordagem à administração oral de peptídeos consiste na combinação da utilização de sistemas transportadores com a formação de conjugados fármaco-polímero. O conjugado fármaco-polímero é formulado como nanopartículas, de modo que o fármaco fica covalentemente ligado, em vez de ficar retido fisicamente. O sistema CPP foi aplicado na co-polimerização do hormônio peptídico de liberação do hormônio luteinizante (LHRH) com o monômero $n$-butilcianoacrilato (nBCA). As partículas formadas apresentaram diâmetro médio de $100 \mathrm{~nm}$ e mostraram-se estáveis, quando incubadas durante 3 horas em conteúdo luminal do intestino, na raspagem da superfície mucosa e em soro. Os resultados in vitro de transporte através de linhagens celulares caco-2 sugerem que a absorção in vivo é possível (Hillery et al., 1996). Por administração oral a ratos, confirmou-se que as partículas são capazes de transportar o peptídeo conjugado para o sangue, enquanto que o peptídeo na for- 
ma livre não era absorvido. A forma biologicamente ativa do peptídeo é liberada das partículas apenas após a absorção oral do complexo LHRH-CPP intacto (Hillery, Toth, Florence, 1996).

\section{ESCOLHA DE UM MÉTODO DE MICROENCAPSULAÇÃO DE PROTEÍNAS E PEPTÍDEOS}

As proteínas são moléculas de estrutura complexa que, freqüentemente, possuem ligações lábeis e numerosos grupos químicos reativos nas suas cadeias laterais. A escolha do método de encapsulação deve garantir a estabilidade da molécula e a retenção da sua atividade biológica. Alguns dos obstáculos encontrados à microencapsulação das proteínas são a utilização de solventes orgânicos e de temperaturas elevadas, suscetíveis de causar a desnaturação do fármaco. As elevadas velocidades de agitação ou o uso de ultra-sons podem provocar alterações na estrutura tridimensional das proteínas (Burke, 2000; Jung et al., 2000).

Quando se utilizam poliésteres biodegradáveis, pela sua hidrofobia, recorre-se normalmente a métodos que envolvem emulsões, nas quais o fármaco peptídico, normalmente hidrossolúvel, possa ser solubilizado. A presença de solventes orgânicos capazes de desnaturar os fármacos peptídicos (Manning, Patel, Borchardt, 1989) constitui um dos grandes inconvenientes destes métodos, além de outros relacionados com a eliminação do solvente. Os resíduos de solvente nas micropartículas estão sujeitos a regulamentação pelos riscos toxicológicos associados (O'Donnell, McGinity, 1997). Pode-se, ainda, obter baixos rendimentos de encapsulação se o fármaco entrar em contato com a fase aquosa externa (Blanco-Prieto et al., 1998; Ogawa et al., 1988). Na preparação de nanopartículas pelo método da emulsão múltipla em $\mathrm{A} / \mathrm{O} / \mathrm{A}$ é, muitas vezes, necessária a utilização de ultra-som ou turbinas de elevada velocidade, que podem causar a inativação das proteínas. Os novos métodos de deposição interfacial e salting-out causam menor stress às proteínas (Jung et al., 2000).

Na microencapsulação com polímeros acrílicos, são freqüentemente utilizadas técnicas de emulsão/polimerização (Damge et al., 1990; Damge et al., 1997b; Lehr et al., 1992; Lowe, Temple, 1994), que apresentam o inconveniente da natureza tóxica dos monômeros que não reagiram e pela difícil eliminação dos estabilizadores e aditivos usados para prevenir a coalescência do produto final. Em alguns casos, são necessárias elevadas quantidades de solventes orgânicos.

Alguns métodos de microencapsulação, como a coacervação, a reticulação de suspensão, a nebulização e a fluidização, não têm sido muito utilizados porque envolvem a utilização de solventes orgânicos e/ou temperaturas extremas ou condições de $\mathrm{pH}$ que podem inativar a proteína.

A microencapsulação em polímeros naturais recorrendo a métodos de gelificação (Coppi et al., 2001; Lemoine et al., 1998; Mumper et al., 1994; Okhamafe et al., 1996; Polk et al., 1994; Ramadas et al., 2000; Vandenberg et al., 2001) é uma alternativa a considerar. Os hidrogéis poliméricos naturais são inertes perante os fármacos protéicos e os métodos utilizados para preparação das micropartículas não requerem a utilização de solventes orgânicos, temperaturas elevadas ou condições extremas de pH. Além disso, pelo fato de serem termodinamicamente compatíveis com a água e intumescerem em meios aquosos, adquirem elevado conteúdo em água o que contribui para a sua biocompatibilidade (Peppas et al., 2000).

\section{CONCLUSÃO}

O método de microencapsulação a escolher deve ser simples, reprodutível, rápido e fácil de ser transportado para a escala industrial, mas deve, sobretudo, minimizar a perda da atividade biológica do peptídeo ou da proteína a encapsular. Entre os métodos mais utilizados, é freqüente recorrer à utilização de solventes orgânicos, responsáveis por possível desnaturação do agente terapêutico e que podem causar problemas ambientais e riscos para a saúde individual. Também, a polimerização, muito utilizada na obtenção de nanopartículas, apresenta inconvenientes devido à toxicidade relacionada com a presença de monômeros residuais. Os métodos que utilizam polímeros naturais revelam-se, pela ausência de condições drásticas e biocompatibilidade do material de encapsulação utilizado, uma alternativa válida na microencapsulação dos fármacos peptídicos. Nos estudos em que foram aplicadas micropartículas de polímeros naturais foi possível obter eficiências de encapsulação elevadas e uma proteção dos fármacos peptídicos da degradação enzimática no trato gastro-intestinal.

\section{ABSTRACT}

\section{Oral delivery system for peptides and proteins: II. Application of microencapsulation methods}

Choosing an appropriate microencapsulation method to improve the oral bioavailability of peptide drugs depends on the drug physico-chemical properties, operation conditions and selected polymers. Microencapsulation techniques and its application in peptide and protein oral 
delivery are reviewed. Natural polymers and techniques involving no harsh conditions such as extreme $\mathrm{pH}$, high temperature and solvents use are the most important when encapsulating peptide drugs.

UNITERMS: Microencapsulation. Natural polymers. Oral administration. Peptide drugs.

\section{REFERÊNCIAS BIBLIOGRÁFICAS}

AFTABROUCHAD, C.; DOELKER, E. Preparation methods for biodegradable microparticles loaded with water-soluble drugs. STP Pharma Sci., Paris, v. 2, p. $365-$ 380, 1992.

AGARWAL, V.; REDDY, I. K.; KHAN, M. A. Polymethyacrylate based microparticulates of insulin for oral delivery: Preparation and in vitro dissolution stability in the presence of enzyme inhibitors. Int. J. Pharm., Amsterdam, v. 225, p. 31-39, 2001.

AIEDEH, K.; GIANASI, E.; ORIENTI, I.; ZECCHI, V. Chitosan microcapsules as controlled release systems for insulin. J. Microencapsul., London, v. 14, p. 567-576, 1997.

ALLÉMAN, E.; GURNY, R.; DOELKER, E. Drug-loaded nanoparticles - preparation methods and drug targeting issues. Eur. J. Pharm. BioPharm., Stuttgart, v. 39, p. 173191, 1993.

ALLEMANN, E.; LEROUX, J. C.; GURNY, R. Polymeric nano- and microparticles for the oral delivery of peptides and peptidomimetics. Adv. Drug Deliv. Rev., Amsterdam, v. 34, p. 171-189, 1998.

ALPAR, H. O.; EYLES, J. E.; WILLIAMSON, E. D. Oral and nasal immunization with microencapsulated clinically relevant proteins. STP Pharma Sci., Paris, v. 8, p. 31-39, 1998.

ARSHADY, R. Albumin microspheres and microcapsules: methodology of manufacturing techniques. J. Control Release, Amsterdam, v. 14, p. 111-131, 1990.

ARSHADY, R. Preparation of biodegradable microspheres and microcapsules. Part 2. Polyactides and related polyesters. J. Controlled Release, Amsterdam, v. 17, p. 121, 1991.
BAKAN, J. A. Microencapsulation. In: SWARBRICK, J., BOYLAN, J. C., eds. Encyclopedia of Pharmaceutical technology. New York: Marcel Dekker, 1994. v. 9., p. 423-441.

BERNKOP-SCHNURCH, A. The use of inhibitory agents to overcome the enzymatic barrier to perorally administered therapeutic peptides and proteins. J. Control Release, Amsterdam, v. 52, p. 1-16, 1998.

BLANCO-PRIETO, M. J.; FATTAL, E.; PUISIEUX, F.; COUVREUR, P. Nouvelles approches pour l'encapsulation de peptides au sein de microspheres de PLG. Ann. Pharm. Fr., Paris, v. 56, p. 256-263, 1998.

BODMEIER, R.; CHEN, H. Preparation of biodegradable poly(+-)lactide microparticles using a spray-drying technique. J. Pharm. Pharmacol., London, v. 40, p. 754$777,1988$.

BOWERSOCK, T. L.; HOGENESCH, H.; SUCKOW, M.; PORTER, R. E.; JACKSON, R.; PARK, H.; PARK, K. Oral vaccination with alginate microsphere systems. $J$. Control Release, Amsterdam, v. 39, p. 209-220, 1996.

BUNDGAARD, H. The utility of the prodrug approach to improve peptide absorption. J. Control Release, Amsterdam, v. 21, p. 63-72, 1992.

BURGESS, D. J.; HICKEY, A. J. Microsphere technology and applications. In: SWARBRICK, J.; BOYLAN, J. C., eds. Encyclopedia of Pharm.aceutical technology. New York: Marcel Dekker, 1994. v. 10, p. 1-29.

BURKE, P. A. Controlled release protein therapeutics: Effects of process and formulation on stability. In: WISE, D. L., ed. Handbook of Pharm.aceutical controlled release technology. New York: Marcel-Dekker, 2000. p. 661-692.

CARINO, G. P.; JACOB, J. S.; MATHIOWITZ, E. Nanosphere based oral insulin delivery. J. Control Release, Amsterdam, v. 65, p. 261-269, 2000.

CARINO, G. P.; MATHIOWITZ, E. Oral insulin delivery. Adv. Drug Deliv. Rev., Amsterdam, v. 35, p. 249-257, 1999.

CARRASQUILLO, K. G.; CARRO, J. C.; ALEJANDRO, A.; TORO, D. D.; GRIEBENOW, K. Reduction of structural perturbations in bovine serum albumin by nonaqueous microencapsulation. J. Pharm. Pharmacol, London, v. 53, p. 115-120, 2001. 
CASTELLANOS, I. J.; CARRASQUILLO, K. G.; LOPEZ, J.; ALVAREZ, M.; GRIEBENOW, K. Encapsulation of bovine serum albumin in poly(lactide-co-glycolide) microspheres by the solid-in-oil-in-water technique. $J$. Pharm. Pharmacol., London, v. 53, p. 167-178, 2001.

CHANDY, T.; MOORADIAN, D. L.; RAO, G. H. Chitosan/ polyethylene glycol-alginate microcapsules for oral delivery of hirudin. J. App. Polym. Sci., Washington, v. 70, p. 2143-2153, 1998.

CHEN, T. Formulation concerns of protein drugs. Drug Dev. Ind. Pharm., New York, v. 18, p. 1311-1354, 1992.

CHO, N. H.; SEONG, S. Y.; CHUN, K. H.; KIM, Y. H.; KWON, I. C.; AHN, B. Y.; JEONG, S. Y. Novel mucosal immunization with polysaccharide-protein conjugates entrapped in alginate microspheres. J. Control Release, Amsterdam, v. 53, p. 215-224, 1998.

CONWAY, B. R.; ALPAR, H. O. Double emulsion microencapsulation of proteins as model antigens using polylactide polymers: effect of emulsifier on the microsphere characteristics and release kinetics. Eur. $J$. Pharm. BioPharm., Stuttgart, v. 42, p. 42-48, 1996.

COPPI, G.; IANNUCCELLI, V.; LEO, E.; BERNABEI, M. T.; CAMERONI, R. Chitosan-alginate microparticles as a protein carrier. Drug Dev. Ind. Pharm., New York, v. 27, p. 393-400, 2001.

COUVREUR, P.; DUBERNET, C.; PUISIEUX, F. Controlled drug delivery with nanoparticles: current possibilities and future trends. Eur. J. Pharm. BioPharm., Stuttgart, v. 41, p. 2-13, 1995.

CROTTS, G.; PARK, T. G. Preparation of porous and nonporous biodegradable polymeric hollow microspheres. J. Controlled Release, Amsterdam, v. 35, p. 91-105, 1995.

DAMGE, C.; MICHEL, C.; APRAHAMIAN, M.; COUVREUR, P.; DEVISSAGUET, J. P. Nanocapsules as carriers for oral peptide delivery. J. Controlled Release, Amsterdam, v. 13, p. 233-239, 1990.

DAMGE, C.; VONDERSCHER, J.; MARBACH, P.; PINGET, M. Polyalkyl cyanoacrylate nanocapsules as a delivery system in the rat for octreotide, a long-acting somatostatin analog. J. Pharm. Pharmacol.., London, v. 49, p. 949-954, 1997a.
DAMGE, C.; VRANCKX, H.; BALSCHMIDT, P.; COUVREUR, P. Poly(alkyl cyanoacrylate) nanospheres for oral administration of insulin. J. Pharm. Sci., Washington, v. 86, p. 1403-1409, 1997b.

DONBROW, M. Introduction and overview. In: DONBROW, M., ed. Microcapsules and nanoparticles in medicine and Pharmacy. Boca Raton: CRC Press, 1992. p. 1-14.

EYLES, J. E.; ALPAR, H. O.; CONWAY, B. R.; KESWICK, M. Oral delivery and fate of poly(lactic acid) microsphere-encapsulated interferon in rats. J. Pharm. Pharmacol., London, v. 49, p. 669-674, 1997.

FIX, J. A. Strategies for delivery of peptides utilizing absorption-enhancing agents. J. Pharm. Sci., Washington, v. 85, p. 1282-1285, 1996.

GEARY, R. S.; SCHLAMEUS, H. W. Vancomycin and insulin used as models for oral delivery of peptides. $J$. Controlled Release, Amsterdam, v. 23, p. 65-74, 1993.

GIUNCHEDI, P.; CONTE, U. Spray-drying as a preparation method of microparticulate drug delivery systems: overview. STP Pharm.a Sci., Paris, v. 5, p. 276-290, 1995.

GOMBOTZ, W. R.; WEE, S. F. Protein release from alginate matrices. Adv. Drug Deliv. Rev., Amsterdam, v. 31, p. 267-285, 1998

HARI, P. R.; SHARMA, C. P. Comments on 'Modulation of protein release from chitosan-alginate microcapsules using the $\mathrm{pH}$-sensitive polymer hydroxypropyl methyl cellulose acetate succinate'. J. Microencapsul., London, v. 15, p. $525-526,1998$.

HERRMANN, J.; BODMEIER, R. Effect of particle microstructure on the somatostatin release from poly(lactide) microspheres prepared by a W/O/W solvent evaporation method. J. Controlled Release, Amsterdam, v. 36, p. 63-71, 1995.

HILlERY, A. M.; TOTH, I.; FLORENCE, A. T. Copolymerised peptide particles. II: Oral uptake of a novel co-polymeric nanoparticulate delivery system for peptides. J. Controlled Release, Amsterdam, v. 42, p. 6573, 1996. 
HILLERY, A. M.; TOTH, I.; SHAW, A. J.; FLORENCE, A. T. Copolymerized peptide particles (CPP). Part 1. Synthesis, characterization and in vitro studies on a novel oral nanoparticulate delivery system. J. Controlled Release, Amsterdam, v. 41, p. 271-281, 1996.

HINCAL, A. A.; KAS, H. S. Microencapsulation technology: interfacial polymerization method. In: WISE, D. L., ed. Handbook of Pharmaceutical controlled release technology. New York: Marcel Dekker, 2000. p. 271-285.

HIROSUE, S.; MULLER, B. G.; MULLIGAN, R. C.; LANGER, R. Plasmid DNA encapsulation and release from solvent diffusion nanospheres. J. Controlled Release, Amsterdam, v. 70, p. 231-242, 2001.

HOSNY, E. A.; KHAN GHILZAI, N. M.; ALNAJAR, T. A.; ELMAZAR, M. M. Hypoglycemic effect of oral insulin in diabetic rabbits using $\mathrm{pH}$-dependent coated capsules containing sodium salicylate without and with sodium cholate. Drug Dev. Ind. Pharm., New York, v. 24, p. 307311, 1998.

ICHIKAWA, H.; FUKUMORI, Y. New applications of acrylic polymers for thermosensitive drug release. STP Pharma Sci., Paris, v. 7, p. 529-545, 1997.

JAIN, R. A. The manufacturing techniques of various drug loaded biodegradable poly(lactide-co-glycolide) (PLGA) devices. Biomaterials, Amsterdam, v. 21, p. 2475-2490, 2000 .

JUNG, T.; KAMM, W.; BREITENBACH, A.; KAISERLING, E.; XIAO, J. X.; KISSEL, T. Biodegradable nanoparticles for oral delivery of peptides: is there a role for polymers to affect mucosal uptake? Eur. J. Pharm. BioPharm., Stuttgart, v. 50, p. 147-160, 2000.

KAS, H. S.; ONER, L. Microencapsulation using coacervation / phase separation: an overview of the technique and applications. In: WISE, D. L., ed. Handbook of Pharm.aceutical controlled release technology. New York: Marcel-Dekker, 2000. p. 301-328.

KAWASHIMA, Y.; YAMAMOTO, A.; TAKEUCHI, H.; HINO, T.; NIWA, T. Properties of a peptide containing DL-lactide/glycolide copolymer nanospheres prepared by novel emulsion solvent diffusion methods. Eur. $J$. Pharm. BioPharm., Stuttgart, v. 45, p. 41-48, 1998.
KAWASHIMA, Y.; YAMAMOTO, H.; TAKEUCHI, H., KUNO, Y. Mucoadhesive DL-lactide/glycolide copolymer nanospheres coated with chitosan to improve oral delivery of elcatonin. Pharm. Dev. Technol, New York, v. 5, p. 77-85, 2000.

KIDCHOB, T.; KIMURA, S.; IMANISHI, Y. Preparation, structure and release profile of polypeptide microcapsules. J. Controlled Release, Amsterdam, v. 40, p. 285-291, 1996.

KIM, C. K.; LEE, E.-J. The controlled release of blue dextran from alginate beads. Int. J. Pharm., Amsterdam, v. 79, p. 11-19, 1992.

KIM, J. C.; SONG, M. E.; LEE, E.-J.; PARK, S. K.; RANG, M. J.; AHN, H. J. Preparation of microspheres by an emulsification-complexation method. J. Colloid Interface Sci., Amsterdam, v. 248, p. 1-4, 2002.

KIMURA, T.; SATO, K.; SUGIMOTO, K.; TAO, R.; MURAKAMI, T.; KUROSAKI, Y.; NAKAYAMA, T. Oral administration of insulin as poly(vinyl alcohol)-gel spheres in diabetic rats. Biol. Pharm. Bull, Tokyo, v. 19, p. 897-900, 1996.

KREUTER, J. Nanoparticles. In: SWARBRICK, J.; BOYLAN, J. C., eds. Encyclopedia of Pharmaceutical technology, v. 10. New York: Marcel Dekker, 1994. p. 165-190.

LARIONOVA, N. V.; PONCHEL, G.; DUCHENE, D.; LARIONOVA, N. I. Biodegradable cross-linked starch/ protein microcapsules containing proteinase inhibitor for oral protein administration. Int. J. Pharm., Amsterdam, v. 189 , p. $171-178,1999$.

LEHR, C.-M. Lectin-mediated drug delivery: the second generation of bioadhesives. J. Controlled Release, Amsterdam, v. 65, p. 19-29, 2000.

LEHR, C.-M.; BOUWSTRA, J. A.; KOK, W.; DE BOER, A. G.; TUKKER, J. J.; VERHOEF, J. C.; BREIMER, D. D.; JUNGINGER, H. E. Effects of the mucoadhesive polymer polycarbophil on the intestinal absorption of a peptide drug in the rat. J. Pharm. Pharmacol., London, v. 44, p. 402-407, 1992.

LEMOINE, D.; WAUTERS, F.; BOUCHEND' HOMME, S.; PREAT, V. Preparation and characterization of alginate microspheres containing a model antigen. Int. J. Pharm., Amsterdam, v. 176, p. 9-19, 1998. 
LIM, F.; SUN, A. M. Microencapsulation islets as bioartificial endocrine pancreas. Science, Washington, v. 210, p. 908-910, 1980.

LIM, L. Y.; WAN, L. S.; THAI, P. Y. Chitosan microspheres prepared by emulsification and ionotropic gelation. Drug Dev. Ind. Pharm., New York, v. 23, p. 981-985, 1997.

LOWE, P. J.; TEMPLE, C. S. Calcitonin and insulin in isobutylcyanoacrylate nanocapsules: protection against proteases and effect on intestinal absorption in rats. $J$. Pharm. Pharmacol., London, v. 46, p. 547-552, 1994.

LOWMAN, A. M.; MORISHITA, M.; KAJITA, M.; NAGAI, T.; PEPPAS, N. A. Oral delivery of insulin using $\mathrm{pH}$ responsive complexation gels. J. Pharm. Sci., Washington, v. 88, p. 933-937, 1999.

LUEBEN, H. L.; RENTEL, C.-O.; KOTZE, A. F.; LEHR, C.-M.; DE BOER, A. G.; VERHOEF, J. C.; JUNGINGER, H. E. Mucoadhesive polymers in peroral peptide drug delivery. IV. Polycarbophil and chitosan are potent enhancers of peptide transport across intestinal mucosae in vitro. J. Controlled Release, Amsterdam, v. 45, p. 15-23, 1997.

LUZZI, L. A. Microencapsulation. J. Pharm. Sci., Washington, v. 59, p. 1367-1376, 1970.

MA, X. Y.; PAN, G. M.; LU, Z.; HU, J. S.; BEI, J. Z.; JIA, J. H.; WANG, S. G. Preliminary study of oral polylactide microcapsulated insulin in vitro and in vivo. Diabetes Obes. Metab., v. 2, p. 243-250, 2000.

MANNING, M. C.; PATEL, K.; BORCHARDT, R. T. Stability of protein pharmaceuticals. Pharm. Res., Stuttgart, v. 6, p. 903-918, 1989.

MATHIOWITZ, E.; JACOB, J. S.; JONG, Y. S.; CARINO, G. P.; CHICKERING, D. E.; CHATURVEDI, P.; SANTOS, C. A.; VIJAYARAGHAVAN, K.; MONTGOMERY, S.; BASSETT, M.; MORRELL, C. Biologically erodable microspheres as potential oral drug delivery systems. Nature, London, v. 386, p. 410-414, 1997.

MORISHITA, I.; MORISHITA, M.; TAKAYAMA, K.; MACHIDA, Y.; NAGAI, T. Hypoglycemic effect of novel oral microspheres of insulin with protease inhibitor in normal and diabetic rats. Int. J. Pharm., Amsterdam, v. 78, p. 9-16, 1992.
MORISHITA, I.; MORISHITA, M.; TAKAYAMA, K.; MACHIDA, Y.; NAGAI, T. Enteral insulin delivery by microspheres in 3 different formulations using Eudragit L-100 and S-100. Int. J. Pharm., Amsterdam, v. 91, p. 2937, 1993.

MUMPER, R. J.; HOFFMAN,A.; PUOLAKKAINEN, P. A.; BOUCHARD, L. S.; GOMBOTZ, W. R. Calciumalginate beads for the oral delivery of transforming growth factor- $\beta 1$ (TGF- $\left.\beta_{1}\right)$ : Stabilization of TGF- $\beta_{1}$ by the addition of polyacrylic acid within acid-treated beads. $J$. Controlled Release, Amsterdam, v. 30, p. 241-251, 1994.

MURATA, Y.; MAEDA, T.; MIYAMOTO, E.; KAWASHIMA, S. Preparation of chitosan-reinforced alginate gel beads - efects of chitosan on gel matrix erosion. Int. J. Pharm., Amsterdam, v. 96, p. 139-145, 1993.

NAKAMURA, M. et al. Potential efficacy of gelatin microspheres as a new adjuvant for oral vaccination. STP Pharma Sci., Paris, v. 8, p. 67-73, 1998.

O’DONNELL, P. B.; MCGINITY, J. W. Preparation of microspheres by the solvent evaporation technique. $A d v$. Drug Deliv. Rev., Amsterdam, v. 28, p. 25-42, 1997.

OGAWA, Y.; YAMAMOTO, M.; OKADA, H.; YASHIKI, T.; SHIMAMOTO, T. A new technique to efficiently entrap leuprolide acetate onto microcapsules of polylactic acid or copoly(lactic/glycolic) acid. Chem. Pharm. Bull, Tokyo, v. 36, p. 1095-1103, 1988.

OKHAMAFE, A. O.; AMSDEN, B.; CHU, W.; GOOSEN, M. F. Modulation of protein release from chitosanalginate microcapsules using the $\mathrm{pH}$-sensitive polymer hydroxypropyl methylcellulose acetate succinate. $J$. Microencapsul., London, v. 13, p. 497-508, 1996.

OPPENHEIM, R. C.; STEWART, N. F.; GORDON, L.; PATE, H. M. Production and evaluation of orally administered insulin nanoparticles. Drug Dev. Ind. Pharm., New York, v. 8, p. 531-546, 1982.

PATIL, R. T.; SPEAKER, T. J. Water-based microsphere delivery system for proteins. J. Pharm. Sci., Washington, v. 89, p. $9-15,2000$.

PEPPAS, N. A.; BURES, P.; LEOBANDUNG, W.; ICHIKAWA, H. Hydrogels in pharmaceutical formulations. Eur. J. Pharm. BioPharm., Stuttgart, v. 50, p. 27-46, 2000 . 
POLK, A.; AMSDEN, B.; DE YAO, K.; PENG, T.; GOOSEN, M. F. Controlled release of albumin from chitosan-alginate microcapsules. J. Pharm. Sci., Washington, v. 83, p. 178-185, 1994.

PONCELET, D.; LENCKI, R.; BEAULIEU, C.; HALLE, J. P.; NEUFELD, R. J.; FOURNIER, A. Poduction of alginate beads by emulsification/internal gelation. I. Methodology. Appl. Microbiol. Biotechnol., v. 38, p. 3945, 1992.

PUTNEY, S. D.; BURKE, P. A. Improving protein therapeutics with sustained-release formulations. Nat. Biotechnol., New York, v. 16, p. 153-157, 1998.

QUINTANAR-GUERRERO, D.; ALLEMANN, E.; FESSI, H.; DOELKER, E. Preparation techniques and mechanisms of formation of biodegradable nanoparticles from preformed polymers. Drug Dev. Ind. Pharm., New York, v. 24, p. 1113-1128, 1998.

RADWAN, M. A. Enhancement of absorption of insulinloaded polyisobutylcyanoacrylate nanospheres by sodium cholate after oral and subcutaneous administration in diabetic rats. Drug Dev. Ind. Pharm., New York, v. 27, p. 981-989, 2001.

RAFATI, H.; COOMBES, A. G.; ADLER, J.; HOLLAND, J.; DAVIS, S. S. Protein-loaded poly(DL-lactide-coglycolide) microparticles for oral administration: formulation, structural and release characteristics. $J$. Controlled Release, Amsterdam, v. 43, p. 89-102, 1997.

RAMADAS, M.; PAUL, W.; DILEEP, K. J.; ANITHA, Y.; SHARMA, C. P. Lipoinsulin encapsulated alginatechitosan capsules: intestinal delivery in diabetic rats. $J$. Microencapsul., London, v. 17, p. 405-411, 2000.

RAMKISSOON-GANORKAR, C.; LIU, F.; BAUDYS, M.; $\mathrm{KIM}, \mathrm{S}$. W. Modulating insulin-release profile from $\mathrm{pH} /$ thermosensitive polymeric beads through polymer molecular weight. J. Controlled Release, Amsterdam, v. 59, p. 287-298, 1999.

REMUNAN-LOPEZ, C.; LORENZO-LAMOSA, M. L.; VILA-JATO, J. L.; ALONSO, M. J. Development of new chitosan-cellulose multicore microparticles for controlled drug delivery. Eur. J. Pharm. BioPharm., Stuttgart, v. 45, p. 49-56, 1998.
RIBEIRO, A. J.; NEUFELD, R. J.; ARNAUD, P.; CHAUMEIL, J. C. Microencapsulation of lipophilic drugs in chitosan-coated alginate microspheres. Int. J. Pharm., Amsterdam, v. 187, p. 115-123, 1999.

RUBINSTEIN, A. et al. Rationale for peptide drug delivery to the colon and the potential of polymeric carriers as effective tools. J. Controlled Release, Amsterdam, v. 46, p. 59-73, 1997.

$\mathrm{SAH}, \mathrm{H}$. Protein behavior at the water/methylene chloride interface. J. Pharm. Sci., Washington, v. 88, p. 1320$1325,1999$.

SILVA, C.; RIBEIRO, A.; FERREIRA, D.; VEIGA, F. Administração oral de peptídeos e proteínas: III. Aplicação à insulina. Rev. Bras. Cien. Farm., São Paulo, v. 39, n. 1, p. 21-40, 2003.

SILVA, C.; RIBEIRO, A.; FERREIRA, D.; VEIGA, F. Administração oral de peptídios e proteínas: I. Estratégias gerais para aumento da biodisponibilidade oral. Rev. Bras. Cienc. Farm, São Paulo, v. 38, p. 125-140, 2002 b.

SAKUMA, S. et al. Oral peptide delivery using nanoparticles composed of novel graft copolymers having hydrophobic backbone and hydrophilic branches. Int. J. Pharm., Amsterdam, v. 149, p. 93-106, 1997.

SARCIAUX, J. M.; ACAR, L.; SADO, P. A. Using microemulsion formulations for oral drug delivery of therapeutic peptides. Int. J. Pharm., Amsterdam, v. 120, p. 127-136, 1995.

SCHUGENS, C.; LARUELLE, N.; NIHANT, R.; JEROME, P.; TEYSSIE, P.; AL., E. Effect of the emulsion stability on the morphology and porosity of semicrystalline poly L-lactide microparticles prepared by W/O/W double emulsion-evaporation. J. Controlled Release, Amsterdam, v. 32, p. 161-176, 1994.

SERRES, A.; BAUDYS, M.; KIM, S. W. Temperature and $\mathrm{pH}$-sensitive polymers for human calcitonin delivery. Pharm. Res, Stuttgart, v. 13, p. 196-201, 1996.

SHAH, D.; SHEN, W. C. Transcellular delivery of an insulintransferrin conjugate in enterocyte-like Caco-2 cells. $J$. Pharm. Sci., Washington, v. 85, p. 1306-1311, 1996. 
SHU, X. Z.; ZHU, K. J. Chitosan/gelatin microspheres prepared by modified emulsification and ionotropic gelation. J. Microencapsul., London, v. 18, p. 237-245, 2001.

SOPPIMATH, K. S.; AMINABHAVI, T. M.; KULKARNI, A. R.; RUDZINSKI, W. E. Biodegradable polymeric nanoparticles as drug delivery devices. J. Control Release, Amsterdam, v. 70, p. 1-20, 2001.

SORIANO, I.; DELGADO, A.; DIAZ, R. V.; EVORA, C. Use of surfactant in polylactic acid protein microspheres. Drug Dev. Ind. Pharm., New York, v. 21, p. 549-558, 1995.

SRIAMORNSAK, P. Investigation of pectin as a carrier for oral delivery of proteins using calcium pectinate gel beads. Int. J. Pharm., Amsterdam, v. 169, p. 213-220, 1998.

SUZUKI, A.; MORISHITA, M.; KAJITA, M.; TAKAYAMA, K.; ISOWA, K.; CHIBA, Y.; TOKIWA, S.; NAGAI, T. Enhanced colonic and rectal absorption of insulin using a multiple emulsion containing eicosapentaenoic acid and docosahexaenoic acid. $J$. Pharm. Sci., Washington, v. 87, p. 1196-1202, 1998.

TAKAHATA, H.; LAVELLE, E. C.; COOMBES, A. G.; DAVIS, S. S. The distribution of protein asociated with poly(DL-lactide-co-glycolide) microparticles and its degradation in simulated body fluids. $J$. Controlled Release, Amsterdam, v. 50, p. 237-246, 1998.

TAKEUCHI, H.; YAMAMOTO, H.; KAWASHIMA, Y. Mucoadhesive nanoparticulate systems for peptide drug delivery. Adv. Drug Deliv. Rev., Amsterdam, v. 47, p. 3954, 2001.
TRENKTROG, T.; MULLER, B. W.; SEIFERT, J. In vitroinvestigation into the enhancement of intestinal peptide absorption by emulsion systems. Eur. J. Pharm. BioPharm., Stuttgart, v. 41, p. 284-290, 1995.

UCHIDA, T.; YASUDA, N.; MATSUYAMA, K. Preparation and characterization of biodegradable or enteric-coated microspheres containing the protease inhibitor camostat. J. Pharm. Pharmacol., London, v. 53, p. 255-261, 2001.

VANDENBERG, G. W.; DROLET, C.; SCOTT, S. L.; DE LA NOUE, J. Factors affecting protein release from alginate-chitosan cocervate microcapsules during prodution and gastric/intestinal simulation. J. Controlled Release, Amsterdam, v. 77, p. 297-307, 2001.

WAN, L. S.; HENG, P. W.; CHAN, L. W. Drug encapsulation in alginate microspheres by emulsification. $J$. Microencapsul., London, v. 9, p. 309-316, 1992.

WEHRLE, P.; MAGENHEIM, B.; BENITA, S. Influence of process parameters on the PLA nanoparticle size distribution, evaluated by means of factorial design. Eur. J. Pharm. BioPharm., Stuttgart, v. 41, p. 19-26, 1995.

YOO, H. S.; CHOI, H. K.; PARK, T. G. Protein-fatty acid complex for enhanced loading and stability within biodegradable nanoparticles. J. Pharm. Sci., Washington, v. 90, p. 194-201, 2001.

Recebido para publicação em 21 de junho de 2002. 